\title{
Expression and Secretion of Human Epidermal Growth Factor in Escherichia coli
}

\author{
Akira Iто, Tomoko Катон, Hideyuki Gomi, Fumitaka Kishimoto, \\ Hideo Agui, ${ }^{\dagger}$ Shigeo Ogino, Koji Yoda, ${ }^{*}$ \\ Makari YAMASAKI* and Gakuzo TAMURA ${ }^{\dagger \dagger}$ \\ Biotechnology Laboratory, Takarazuka Research Center, Sumitomo Chemical Co., \\ 4-2-1, Takatsukasa, Takarazuka, Hyogo 665, Japan \\ * Department of Agricultural Chemistry, The University of Tokyo, \\ 1-1-1, Yayoi, Bunkyo-ku, Tokyo 113, Japan
}

Received August 9, 1985

\begin{abstract}
E. coli 294 cells were transformed with a plasmid containing a hybrid gene in which the sequence encoding mature human epidermal growth factor (hEGF) was joined to the closed sequence encoding the signal peptide of $E$. coli alkaline phosphatase. During phosphate limitation these cells secreted hEGF to the periplasmic space.
\end{abstract}

Human epidermal growth factor (hEGF), $\mathrm{MW}=6000$, is a singlechain polypeptide consisting of 53 amino acids ${ }^{1)}$ synthesized in the duodenum and salivary glands. ${ }^{2)}$ This polypeptide hormone inhibits gastric acid secretion $^{3)}$ and greatly stimulates epithelial cell proliferation. ${ }^{4)}$ Because of its gastric antisecretory activity it may be useful in the treatment of duodenum ulceration. We intended to produce this polypeptide hormone in $E$. coli using recombinant DNA technology.

In an $E$. coli system, a cloned gene product can be secreted into the periplasmic space by fusing an appropriate signal peptide to the amino terminal end of the gene product. It is advantageous to do this because the gene product is more stable in the periplasmic space than in the cytoplasmic space $^{5)}$ probably because there is less protease. Also, the purification of the product will be much easier if the product is in the periplasmic space, and some enzymes or proteins are toxic for the host cell and inhibit its growth when in the cytoplasmic space. From the industrial viewpoint, it is desirable that these enzymes or proteins be secreted to the outside of the cytoplasmic membrane while being synthesized.

The alkaline phosphatase (APase) of E. coli is in the periplasm ${ }^{6,7)}$ and much is synthesized under low phosphate conditions. ${ }^{8)}$ The protein is synthesized as a precursor with a signal peptide at the $\mathrm{N}$-terminus ${ }^{9)}$ and the mature form is secreted after the signal peptide is processed. ${ }^{10)}$ It was anticipated that hEGF would be transported to the periplasmic space if we fused the APase signal peptide to the Nterminus of hEGF.

We report here the construction of APase signal peptide-hEGF hybrid genes, and the expression and secretion of the product. We also report the effects of alteration of amino acids near the signal peptide processing site on the secretion of hEGF.

\section{MATERIALS AND METHODS}

Bacterial strains and plasmids. E. coli $\mathrm{K} 12$ strain 294 (endoI ${ }^{-}, t h i^{-}, \mathrm{r}_{\mathrm{k}}{ }^{-}, \mathrm{m}_{\mathrm{k}}{ }^{-}$), kindly provided by Dr. Negoro

$\dagger$ To whom correspondence should be addressed.

${ }^{\dagger}$ Present address: Department of Applied Biological Science, Science University of Tokyo, 2641, Yamazaki, Nodashi, Chiba, 278, Japan. 
of the University of Osaka, was used in all experiments as the host cell.

E. coli plasmids pYK264, pYK278, and pYK331 were constructed by Kikuchi et al. (submitted for publication) for the expression and secretion of proteins in E. coli. They bear the promoter, operator, and signal peptide coding regions of $E$. coli alkaline phosphatase and successive cloning sites. Both pMRLIU30 and pINUG1 are plasmids constructed for the direct expression of hEGF in the cytoplasmic space of $E$. coli and will be described elsewhere. pINIIUG is a plasmid for the expression and secretion of hEGF in $E$. coli and was constructed as follows. pINUG1 was digested with ClaI and SalI and a fragment of about $900 \mathrm{bp}$ containing the hEGF gene was isolated. Cohesive ends were filled in with the Klenow fragment. The expression vector pINIIB $1^{24)}$ was digested with EcoRI and the resulting cohesive ends were filled in with the Klenow fragment. The fragment of about $900 \mathrm{bp}$ was inserted into this site to make pINIIUG.

Enzymes and chemicals. Restriction nucleases, the Klenow fragment, and T4 DNA ligase were purchased from Takara Shuzo Co., Ltd. (Kyoto, Japan). Each enzyme was used according to the manufacturer's specifications. Ampicillin was purchased from Meiji Seika Kaisha, Ltd.

Preparation of plasmids and DNA fragments. Plasmids were prepared by the rapid alkaline method ${ }^{11)}$ and purified by $\mathrm{CsCl}$ equilibrium density gradient centrifugation. DNA fragments generated by restriction enzyme digestion were separated by agarose gel or polyacrylamide gel and electroeluted from the gel slices.

Transformation. For transformation, recipient cells grown to $3 \times 10^{8}$ cells per $\mathrm{ml}$ in $200 \mathrm{ml}$ of $\mathrm{L}$ broth were centrifuged for $10 \mathrm{~min}$ at $6000 \mathrm{rpm}$ at $4^{\circ} \mathrm{C}$. The pellet was suspended in $50 \mathrm{ml}$ of cold $0.1 \mathrm{M} \mathrm{MgCl}_{2}$ solution, and collected by centrifugation. The pellet was resuspended in $50 \mathrm{ml}$ of ice cold $0.1 \mathrm{M} \mathrm{CaCl}_{2}$ solution and kept at $0^{\circ} \mathrm{C}$ for $20 \mathrm{~min}$. Cells were harvested by centrifugation and resuspended in $15 \mathrm{ml}$ of ice cold $0.1 \mathrm{M} \mathrm{CaCl}_{2}-15 \%$ glycerol solution to give competent cells.

For transformation, 10 to $20 \mu \mathrm{l}$ of plasmid DNA in $\mathrm{H}_{2} \mathrm{O}$ $(0.5$ to $1.0 \mu \mathrm{g})$ was added to $300 \mu \mathrm{l}$ of competent cells and kept on ice for at least $40 \mathrm{~min}$. After incubation at $42^{\circ} \mathrm{C}$ for $3 \mathrm{~min}$, the mixture was added to $5 \mathrm{ml}$ of $\mathrm{L}$ broth and cultured at $37^{\circ} \mathrm{C}$ for $60 \mathrm{~min}$. The mixture was spread on a selective medium and transformants were selected.

Media and culture conditions. L broth ( $\mathrm{pH} 7.0$ ) contained $10 \mathrm{~g}$ of polypeptone, $5 \mathrm{~g}$ of Yeast extract, and $5 \mathrm{~g}$ of $\mathrm{NaCl}$ per liter of water. Low phosphate medium (121 medium, $\mathrm{pH} 7.5$ ) contained $4 \mathrm{~g}$ of glucose, $4.68 \mathrm{~g}$ of $\mathrm{NaCl}$, $1.5 \mathrm{~g}$ of $\mathrm{KCl}, 1.3 \mathrm{~g}$ of $\mathrm{NH}_{4} \mathrm{Cl}, 0.4 \mathrm{~g}$ of $\mathrm{Na}_{2} \mathrm{SO}_{4}, 0.2 \mathrm{~g}$ of $\mathrm{MgCl}_{2}, 0.03 \mathrm{~g}$ of $\mathrm{CaCl}_{2}, 12 \mathrm{~g}$ of Trizma base, $0.5 \mathrm{mg}$ of $\mathrm{FeCl}_{3}$, and $0.3 \mathrm{mg}$ of $\mathrm{ZnCl}_{2}$ per liter of water. All media used to grow cells carrying plasmids contained $50 \mu \mathrm{g} / \mathrm{ml}$ of ampicillin unless otherwise mentioned.

Transformants were grown overnight in $5 \mathrm{ml}$ of $\mathrm{L}$ broth. One milliliter of the overnight culture was inoculated into $200 \mathrm{ml}$ of $\mathrm{L}$ broth and grown to $A_{550}=0.7$. Cells were collected by centrifugation $(6000 \mathrm{rpm} \times 10 \mathrm{~min})$ and washed once with $50 \mathrm{ml}$ of cold low phosphate medium (121 medium) and collected again. The pellet was resuspended in $200 \mathrm{ml}$ of low phosphate medium and cultured for derepression. Samples were taken at various times for measurement of hEGF activity. All cultivations were done at $37^{\circ} \mathrm{C}$.

Cell fractionation. The periplasmic fraction was prepared by the cold osmotic shock procedure ${ }^{12)}$ with all of the operations were done in a small volume using an Eppendorf centrifugation microtube. A mixture of the cytoplasmic and membrane fractions was prepared by treatment of the pellet obtained after cold osmotic shock with lysozyme and Triton X-100. In this procedure, more than $95 \%$ of the $\beta$-galactosidase activity was observed in the mixture of cytoplasmic and membrane fractions, while more than $95 \%$ of the $\beta$-lactamase activity was observed in the periplasmic fraction.

Assay of $h E G F$. hEGF was assayed by a competitive receptor binding assay using ${ }^{125} \mathrm{I}$-labeled mouse EGF (Amersham) and EGF receptor prepared from rat liver. ${ }^{13,14)}$ This method is based on the ability of both mouse epidermal growth factor (mEGF) and human epidermal growth factor (hEGF) to compete with ${ }^{125}$ I-labeled mEGF for binding sites on the membrane of rat liver. Membranes from rat liver were isolated as described. ${ }^{15)}$ Standard curves were obtained by measuring the effects of increasing quantities of mouse EGF on the binding of a constant amount of ${ }^{125} \mathrm{I}$-labeled mouse EGF.

Oligonucleotide-directed mutagenesis. Oligonucleotide directed mutagenesis was done by the method of Zoller et al. ${ }^{16)}$ The oligonucleotide used as primer $\left({ }^{5}\right.$ CGATGAATTCTGACTCCG $\left.{ }^{3}\right)$ was synthesized by a DNA synthesizer from the Applied Biosystem Co.

\section{RESULTS}

\section{1) Construction of plasmid}

For the expression and secretion of hEGF in E. coli, we have constructed plasmid pYKUG30 according to the scheme shown in Fig. 1a. We did oligonucleotide-directed mutagenesis to create a new EcoRI site immediately after the initiation codon shown by arrowheads in Fig. 1a. An approximately 900 bp HindIII-SalI fragment containing the hEGF gene with a point mutation was inserted 


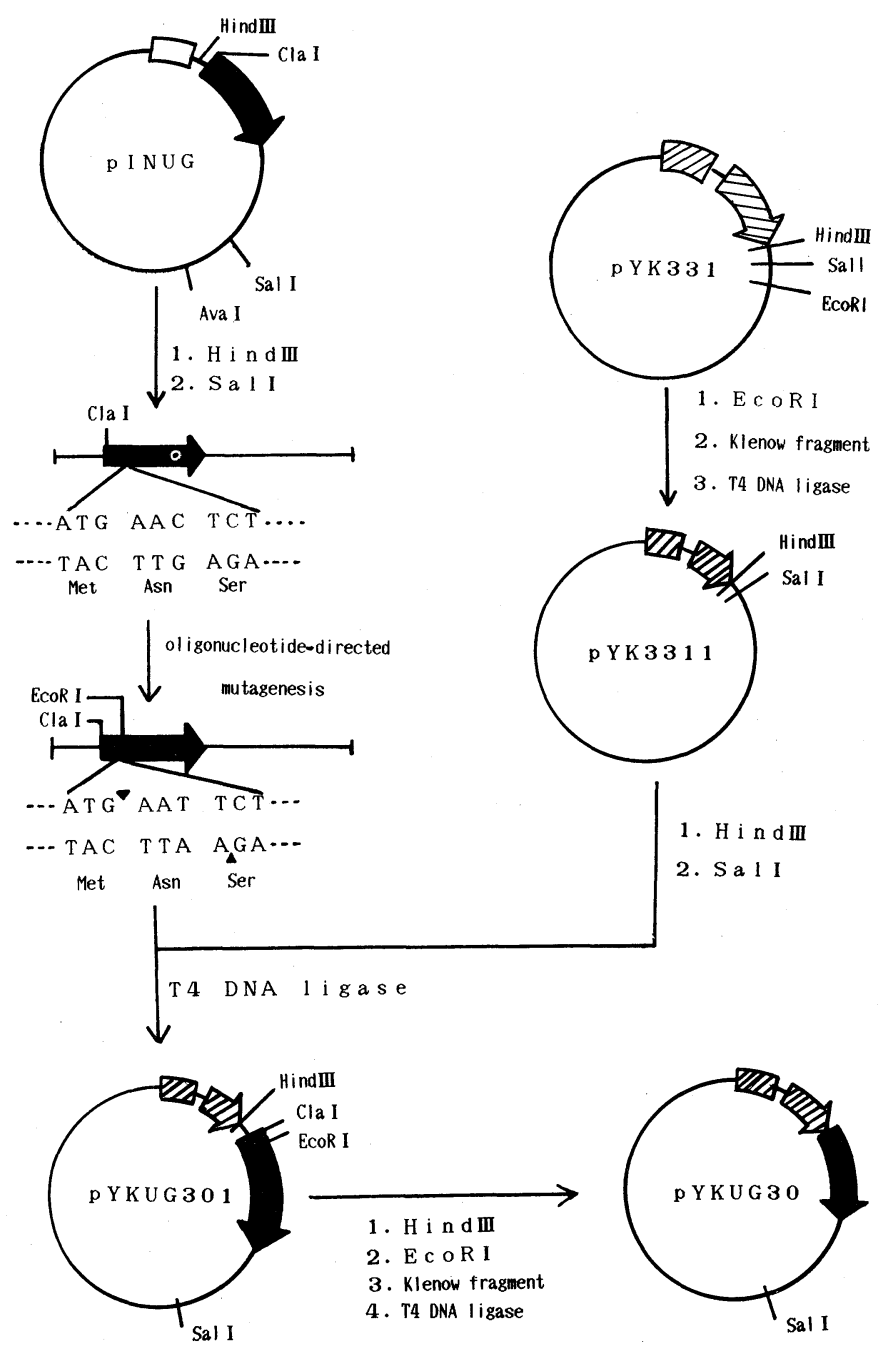

(a)

FIG. 1. Construction of Expression Plasmids (a) pYKUG30; New EcoRI Site Created as a Result of Oligonucleotide-directed Mutagenesis Is Indicated by Arrowheads (b) pYKUG15, pYKUG17, pYKUG14 and pYKUG10.

$\square$, promoter of $E$. coli lpp gene. $\Rightarrow$, signal peptide coding region of $E$. coli lpp gene.

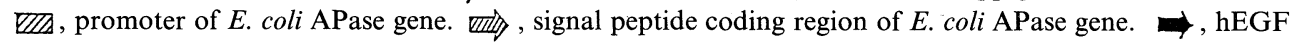
gene.

into the HindIII-SalI site of pYKUG3311 to get pYKUG301. A short HindIII-EcoRI fragment of pYKUG301 was deleted to get pYKUG30. In pYKUG30, the region encoding the mature hEGF was fused in frame to the region encoding the signal peptide of $E$. coli APase. The amino acid sequence of the presecretory protein encoded by this hybrid gene is shown in Fig. 2.

\section{2) Production and location of hEGF expressed in E. coli}

Plasmid pYKUG30 bearing the $E$. coli APase signal peptide-hEGF hybrid gene was used to transform E. coli 294 and ampicillin resistant transformants were selected. Transformants were grown in rich medium (L broth) to $A_{550}=0.7$. Cells were harvested and shifted to low phosphate medium (121 medium). 

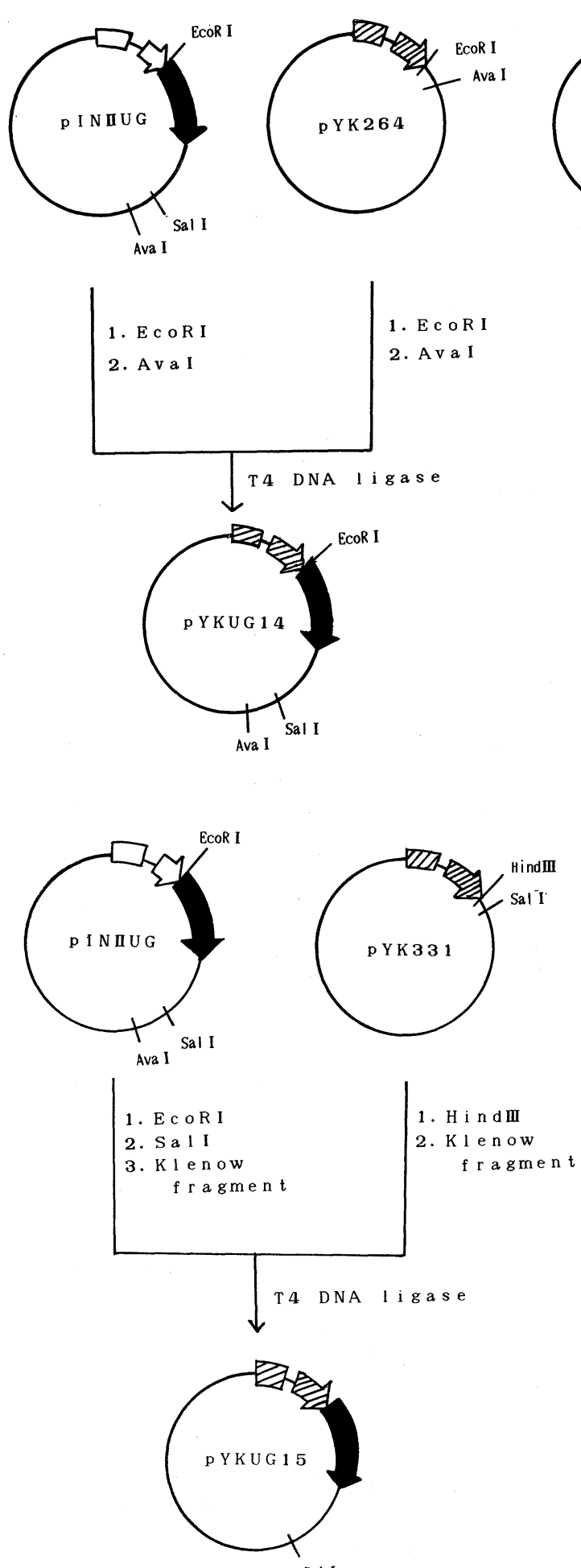

Sal I
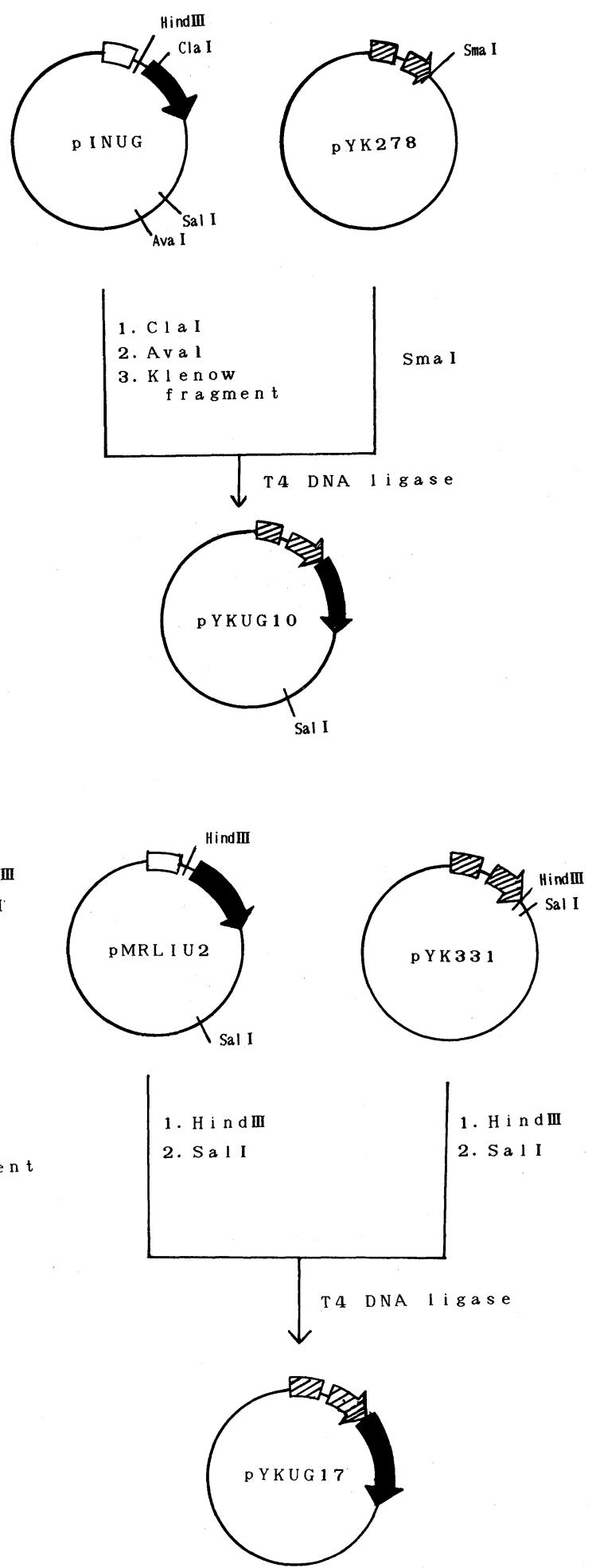

(b) 
$\longleftarrow$ Signal peptide of Apase-

Met-Lys-GIn-Ser-Thr-Ile-Ala-Leu-Ala-Leu-Leu-Pro-Leu-Leu-Phe-

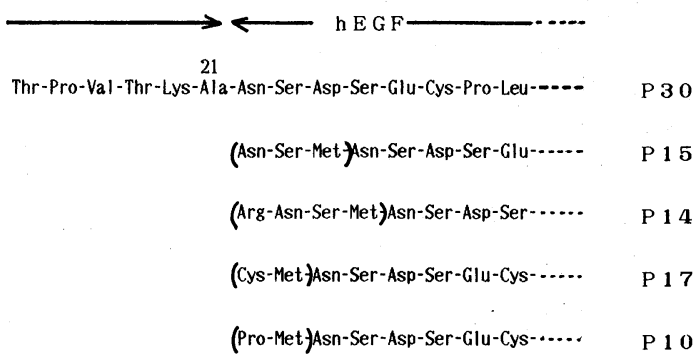

Fig. 2. N-Terminal Amino Acid Sequences of Presecretory Proteins Encoded by the Gene Contained in Plasmids pYKUG30, pYKUG15, pYKUG14, pYKUG17, and pYKUG10.

Signal peptide of $E$. coli APase and N-terminus of mature hEGF are indicated by arrows above the amino acid sequences. Additional amino acid residues inserted between the end of APase signal peptide and N-terminus of hEGF are shown in italics. P30, P15, P14, P17, and P10 represent presecretory proteins encoded by the genes contained in plasmids pYKUG30, pYKUG15, pYKUG14, pYKUG17, and pYKUG10, respectively.

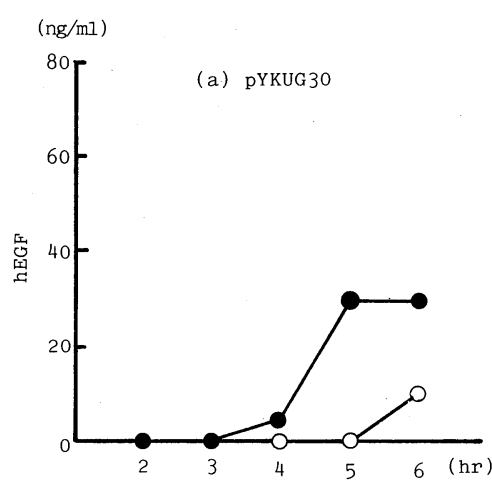

time after derepression
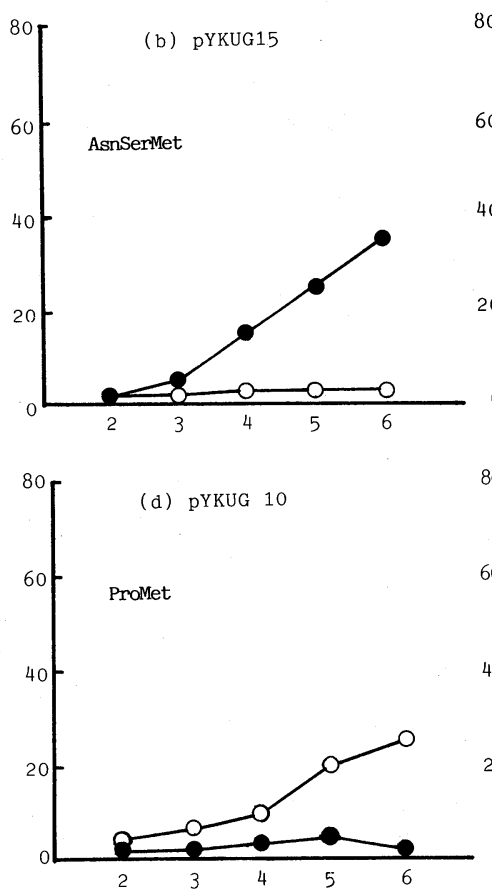
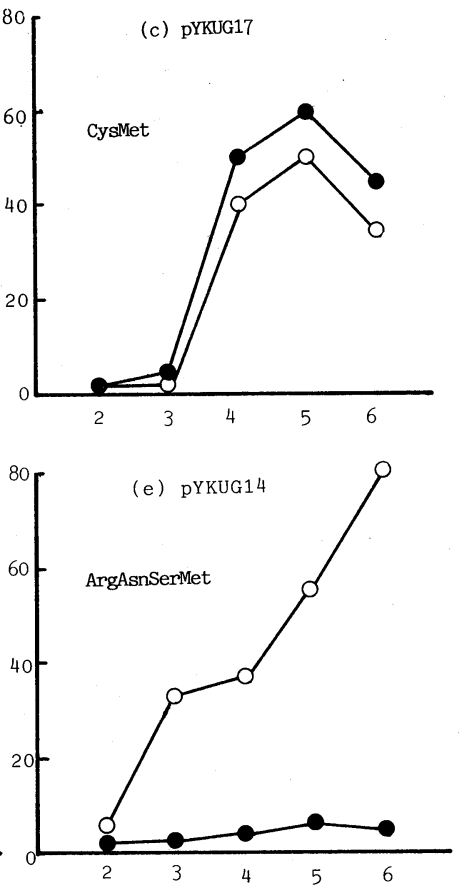

FIG. 3. Production and Localization of hEGF Produced by E. coli Harboring (a) pYKUG30, (b) pYKUG15, (c) pYKUG17, (d) pYKUG10, or (e) pYKUG14.

Cells were grown in L-broth to $A_{550}=0.7$ and shifted to 121 medium at time $0 \mathrm{hr}$. - - hEGF activity in the periplasmic fraction. - - - hEGF activity in the cytoplasmic fraction and membrane fraction. The additional amino acid sequences inserted between the end of APase signal peptide and the N-terminus of mature hEGF are also shown. 
Samples were taken at various times to permit the measurement of hEGF activity and to locate it in the cell.

hEGF activity in each fraction of $E$. coli containig pYKUG30 is shown in Fig. 3a. hEGF activity in the periplasmic fraction was observed from $4 \mathrm{~h}$ after derepression and approximately $30 \mathrm{ng} / \mathrm{ml}$ of hEGF was observed 5 to $6 \mathrm{~h}$ after derepression. On the other hand, not more than $10 \mathrm{ng} / \mathrm{ml}$ of hEGF was observed in the mixture of cytoplasmic and membrane fractions.

3) Effects of the amino acid sequence near processing site on the secretion of $h E G F$

To analyze the effects of amino acid sequences near the processing site on the secretion of hEGF, we have constructed four more plasmids, pYKUG15, pYKUG10, pYKUG14, and pYKUG17, according to the scheme shown in Fig. 1b. In each plasmid, the region coding for the mature hEGF is fused in frame to the region coding for the signal peptide of $E$. coli APase, as in pYKUG30, with sequences coding for two to four additional amino acids between them (Fig. 2). To construct pYKUG15, pYKUG10, pYKUG14, and pYKUG17, we used the expression vectors pYK331,
pYK278, pYK264, and pYK331, respectively.

Plasmids pYKUG15, pYKUG10, pYKUG14, and pYKUG17 were used to transform E. coli 294. Ampicillin-resistant transformants were selected and tested for hEGF activity as indicated above. hEGF activities in each fractions of $E$. coli containing pYKUG15, pYKUG10, pYKUG14, or pYKUG17 are shown in Fig. $3 b \sim$ e.

$E$. coli cells harboring pYKUG15 and pYKUG17 secreted hEGF into the periplasmic fraction as in the case of pYKUG30. E. coli cells harboring pYKUG17 secreted up to $60 \mathrm{ng} / \mathrm{ml} \mathrm{hEGF}$ into the periplasmic space while about same amount of activity was observed in the mixture of cytoplasmic and membrane fractions. However, no hEGF activity was observed in the mixture of cytoplasmic and membrane fractions of cells harboring pYKUG15. E. coli cells harboring pYKUG10 or pYKUG14 did not secrete hEGF into the periplasmic fraction unlike those with pYKUG30, pYKUG15, and pYKUG17. All of the hEGF activity was observed in the mixture of cytoplasmic and membrane fractions.

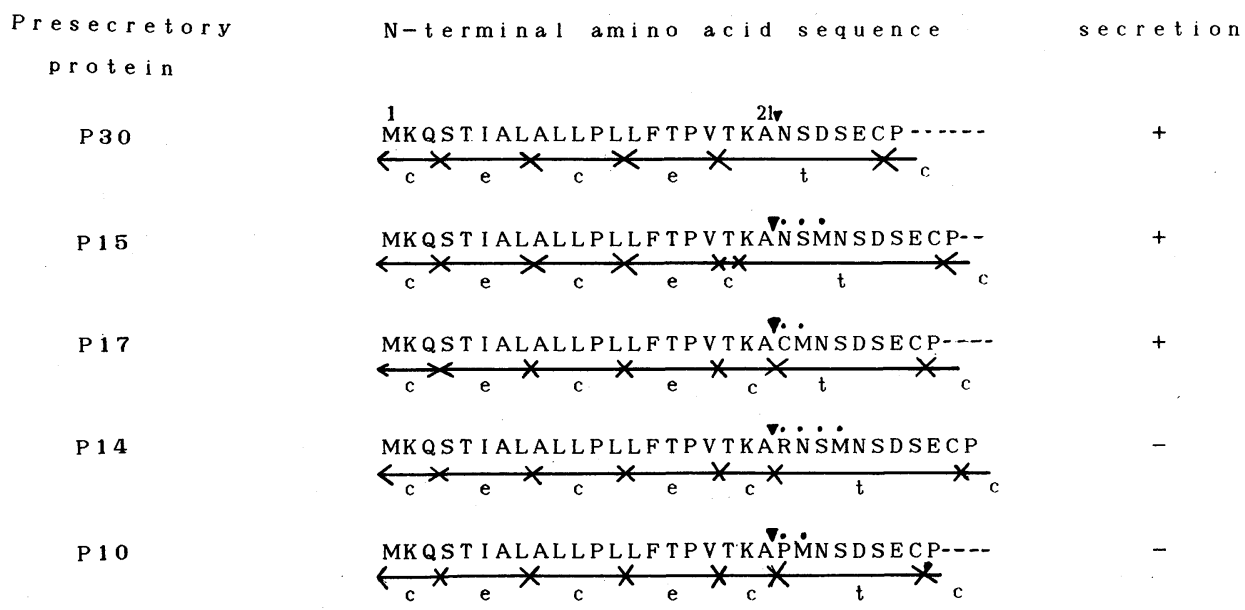

FIG. 4. Predicted Secondary Structure of Presecretory Proteins P30, P15, P17, P14, and P10.

Secondary structure of the N-terminal region are shown. c, e, and t represent $\alpha$-helix, $\beta$-sheet, and $\beta$-turn, respectively. Dots $(\bigcirc)$ above the amino acid sequence indicate additional amino acid residues inserted between the end of APase signal peptide and N-terminus of hEGF. 
4) Prediction of secondary structure of the presecretory proteins

To discover the relationship between secretion and secondary structure of the presecretory protein, the secondary structure of the presecretory proteins were predicted by the method of Chou and Fasman ${ }^{23)}$ (Fig. 4). In all five presecretory proteins P30, $\mathrm{P} 15, \mathrm{P} 14, \mathrm{P} 17$, and $\mathrm{P} 10$, a $\beta$-turn structure appears immediately before or after the putative processing site after an alanine residue.

\section{DISCUSSION}

We have shown that the E. coli alkaline phosphatase signal peptide directs the secretion of human epidermal growth factor into the periplasmic space of E. coli. hEGF activity was observed in the periplasmic fraction in the cells carrying pYKUG30. This indicates that the secretion apparatus of $E$. coli could recognize the APase signal peptide-hEGF hybrid protein as a presecretory protein.

We had tried to have hEGF expressed in the cytoplasmic space of $E$. coli. Using strong promoters such as trp, lpp, and lacUV5, resulted in low levels of production (about $10^{2}$ molecules per cell). The instability of hEGF in the cytoplasmic space of $E$. coli was considered to be the main reason for the low production. This is instriking contrast to the high production of the same protein (about $3 \times 10^{4}$ molecules per cell) when using the APase expression and secretion system reported here. Only cells transformed with high copy number runaway type plasmids could produce the same amount of hEGF in the cytoplasmic space. These results will be reported elsewhere.

Thus we have demonstraed that a secretion cloning system using pYK series expression vectors has significant advantage when the product is though to be be unstable in the cytoplasmic space. According to Perlman et al., ${ }^{22)}$ the most probable signal peptide processing site is predicted to be after the alanine residue at position 21 (counting from the $\mathrm{N}$ terminus residue, methionine, of the APase signal peptide at position 1. Fig. 2). Therefore, the product is thought to have no extra amino acids at the $\mathrm{N}$-terminus and can be mature hEGF in the case of pYKUG30 although we have not yet examined the $\mathrm{N}$-terminal amino acid sequence of the product detected in the periplasmic space.

Presecretory polypeptides characteristically contain a signal peptide at the $\mathrm{N}$-terminus of the protein. ${ }^{17,18)}$ This signal peptide directs insertion of the polypeptide into the membrane and is removed from the nascent polypeptide during secretion. Structural alteration of signal sequences often has dramatic functional consequences. ${ }^{19,20)}$ Analysis of known prokaryotic signal peptide processing sites has indicated features such as the presence of alanine or glycine at the signal peptidase cleavage site, and the absence of proline residue from the region -3 to 1 (counting from the cleavage site between positions -1 and $+1){ }^{21)}$ However, no strongly conserved primary amino acid sequence was found. These findings suggested that not only secondary structure but also other properties of these signal peptides are essential for recognition by the signal peptidase. In the analysis of putative signal peptidase recognition sites and sequence, Perlman et al. have suggested that a $\beta$-turn structure immediately before or after the cleavage site could be important for signal peptidase access to the cleavage site. ${ }^{22)}$

To investigate the importance of a $\beta$-turn structure immediately before or after the cleavage site, we tried P30, P15, P14, P17 and $\mathrm{P} 10$. As described in the Results section, a $\beta$ turn structure was predicted around the putative processing site after the alanine residue in all five presecretory proteins. Therefore, addition of two to four amino acids in this region did not change the secondary structure around the processing site. However, hEGF was not secreted in cells harboring pYKUG10 or pYKUG14 while cells harboring pYKUG15, pYKUG30 and pYKUG17 secreted hEGF into the periplasmic space.

It is noteworthy that, the addition of only one residue at the processing site (P14 contains 
one additional residue, arginine, compared with $\mathrm{P} 15)$ or alteration of only one residue (P10 contains proline in place of cysteine compared with P17) inhibited secretion.

There findings indicate that the $\beta$-turn structure immediately before or after the processing site is not sufficient for the function of the signal peptidase of $E$. coli in contrast to the proposal of Perlman et al.,2) and that the signal peptidase of $E$. coli may discriminate slight differences of amino acid sequences near the processing site, as was also observed by Inouye et al. ${ }^{25}$ )

Although we could demonstrate the importance of the amino acid sequence near the processing site, no relationship between the predicted secondary structure of the presecretory protein and secretion was found. To identify the essential features for specific cleavage it may be important to find the secondary structure of the presecretory protein in a hydrophobic environment. It is necessary to identify these essential features to further improve the usefulness of this secretion cloning system.

\section{REFERENCES}

1) H. Gregory and B. M. Preston, Int. J. Peptide Protein Res., 9, 107 (1977).

2) P. U. Heitz, M. Kasper, A. Pola. Van Neoden, J. M. H. Gregory and A. G. E. Pearse, Gut, 19, 408 (1978).

3) J. B. Elder, P. C. Gauguli, I. E. Gillespie, I. Delamore and $\mathrm{H}$. Gregory, Lancet, 1975, 424.

4) J. B. Elder, P. C. Gauguli, I. E. Gellespie, E. L. Gerring and H. Gregory, Gut, 16, 887 (1975).
5) K. Talmadge and W. Gilbert, Proc. Natl. Acad. Sci. U.S.A., 79; 1830 (1982).

6) C. H. Neu and L. A. Heppel, J. Biol. Chem., 240, 3685 (1965).

7) M. Malamy and B. Horecker, Biochem. Biophys. Res. Commun., 5, 104 (1961).

8) A. Torriani, Biochim. Biophys. Acta, 38, 460 (1960).

9) H. Inouye and J. Beckwith, Proc. Natl. Acad. Sci. U.S.A., 74, 1440 (1977).

10) C. Chang, H. Inouye, P. Model and J. Beckwith, $J$. Bacteriol., 142, 726 (1980).

11) H. C. Birnboim and J. Doly, Nucleic Acid Res., 7, 1513 (1979).

12) H. C. Neu and L. A. Heppel, J. Biol. Chem., 241, 3055 (1966)

13) E. O'Keefe, M. D. Hollenberg and P. Cuatrcasas, Archiv. Biochem. Biophys., 164, 518 (1974).

14) M. D. Hollenberg and H. Gregory, Life Sci., 20, 267 (1976).

15) P. Cuatrecasas, Proc. Natl. Acad. Sci. U.S.A., 69, 1277 (1972).

16) M. J. Zoller and M. Smith, Nucleic Acid Res., 10, 6487 (1982).

17) G. Kreil, Ann. Rev. Biochem., 50, 317 (1981).

18) B. D. Davis and P.-C. Tai, Nature (London), 283, 433 (1980).

19) H. Bedouelle, P. J. Bassford, A. V. Fowler, I. Zabin, J. Beckwith and M. Hofnung, Nature (London), 285, 78 (1980).

20) S. D. Emr, J. Hedgpeth, J. M. Clement, T. J. Silhavy and M. Hofnung, Nature (London), 285, 82 (1980).

21) G. von Heijne, J. Mol. Biol., 173, 243 (1984).

22) D. Perlman and H. O. Halvorson, J. Mol. Biol., 167, 391 (1983).

23) P. Y. Chou and G. D. Fasman, Adv. Enzymol., 47, 45 (1978).

24) M. Inouye, "Experimental Manupilation of Gene Expression," ed. by M. Inouye, Academic Press Inc., New York, 1983, p. 15.

25) S. Inouye, Science, 221, 59 (1983). 